\section{Sete cidades: um estudo das representações sociais das cidades brasileiras patrimônio mundial na Web}

\author{
Eliane Bevilacqua Lordello dos Santos Souza \\ Arquiteta e urbanista, doutora em Desenvolvimento Urbano pela \\ Universidade Federal de Pernambuco, Fundação de Amparo à \\ Pesquisa do Espírito Santo, Fundação de Amparo à Pesquisa do \\ Espírito Santo, Av. Vitória, 2045, Bairro Nazareth, CEP 29041-230, \\ Vitoria, ES, (27) 3132-9080, elilordello@gmail.com
}

\title{
Resumo
}

Este artigo relata resultados e desdobramentos da tese de mesmo nome, que tem por objeto as representações sociais na Web das cidades brasileiras tombadas pela UNESCO, visando desvendar tais representações. Seus principais fundamentos são os suportes narrativos de cidades; o patrimônio mundial; a diversidade cultural; a teoria das representações sociais. No estudo empírico aliam-se a tais fundamentos os passos metodológicos sugeridos pela teoria das representações sociais e os métodos analítico-descritivos e de análise do discurso. As representações são desvendadas, relativizadas quanto aos critérios de tombamento, e sugerem-se outras pesquisas.

Palavras-chave: representações sociais, patrimônio mundial, Websites.

1 Este artigo é uma versão ampliada e ilustrada do trabalho apresentado no XIII ENA-ANPUR (Santa Catarina, 2009). O texto parte das reflexões de minha tese de doutorado, intitulada Sete cidades: um estudo das representações sociais das cidades brasileiras patrimônio mundial na Web. A tese foi defendida no Programa de Pós-graduação em Desenvolvimento Urbano da UFPE e orientada pela professora Dra. Norma Lacerda, a quem eu agradeço imensamente. ste trabalho ${ }^{1}$ enfoca as representações sociais das sete cidades brasileiras tombadas pela Organização das Nações Unidas para a Educação, a Ciência e a Cultura (UNESCO) como patrimônio mundial na Web: Ouro Preto (MG), Olinda (PE), Salvador (BA), Brasília (DF), São Luís (MA), Diamantina (MG), Goiás Velho (GO) - este o seu objeto.

O interesse de pesquisá-las na Web advém de serem os websites (ou simplesmente sites) as mais novas mídias da contemporaneidade, bem como de serem os sites as mídias em que as cidades são mais imediata e rapidamente acessíveis na atualidade. Resumidamente, vale dizer que neste trabalho o site é considerado um suporte narrativo, tal como a arquitetura como espaço construído, os livros, revistas e jornais, porém muito mais jovem.

$\mathrm{Na}$ atualidade globalizada e cibercultural, a própria lista da UNESCO, e seus 830 sítios, são acessíveis a partir do site da agência. Dentre outras faculdades, o site da UNESCO possibilita a visualização tridimensional dos sítios, através do programa
Google Earth. Parte importante desses sítios diz respeito a cidades.

Cidades são construções culturais erguidas, materializadas, ao longo da história, em madeira, pedra, aço, concreto. São estruturas físicas, táteis, penetráveis, com as quais se interage fisicamente, afetivamente, de que se guardam lembranças, e das quais se forma uma memória. Mais ainda, as cidades podem ter suas memórias instituídas como patrimônios, em diferentes instâncias, por exemplo, a nacional ou a mundial, como é o caso das cidades tratadas aqui. No caso específico dessas cidades, a representação no universo virtual da Web parece ainda mais complexa, pois enseja a colocação de uma aparente dessemelhança: aquela entre a pátina do tempo, que atinge as cidades, e a idéia de novidade que aparentam os sites. Os websites, além de serem as mais novas mídias, transmitem, de antemão, uma idéia altamente tecnológica. Isso se deve ao fato de essas mídias remeterem a toda uma parafernália eletrônica, a que nem todos têm acesso, daí parecerem ainda uma eterna 
novidade. Desse modo, veiculadas nos sites, as cidades parecem, a princípio, destituídas de sua pátina temporal, como se nelas se colasse a idéia de novidade daquelas mídias.

Diante da realidade da veiculação de cidades tombadas em websites, a inquietação inicial a motivar a tese foi a própria representação das cidades patrimônio mundial nestes novos suportes narrativos da Web, rede caracterizada como multívaga, e de multívia visibilidade. Tais reflexões ensejaram a seguinte pergunta: como são representadas as cidades brasileiras patrimônio mundial nos sites da Web? Eis o problema que move este trabalho. Diante disso, o objetivo aqui é desvendar as representações sociais das cidades brasileiras patrimônio mundial na Web.

O esforço desta pesquisa é, portanto, essencialmente um esforço de descoberta. Para tentar responder àquela questão e atingir o objetivo proposto, lançase mão do estudo empírico das representações sociais das sete cidades nos sites. Pondera-se que o estudo das representações sociais é também uma forma de tentar descobrir se há um senso comum, ou ao menos um consenso, relativamente a essas cidades. Mais ainda: esse estudo é também um modo de desvendar seus possíveis aportes para a compreensão do patrimônio mundial.

A anterior menção ao senso comum abre o atalho para arrazoar, de forma introdutória, sobre a opção pelo estudo das representações sociais e sobre a escolha da teoria das representações sociais como referencial que fundamentará o método usado neste trabalho. O conceito de representações sociais participa da teoria assumida pelo psicólogo romeno (radicado na França) Serge Moscovici. Segundo esse psicólogo caracteriza essencialmente uma representação social o fato de ela constituir uma ordem orientadora, um código nomeante e classificador. Essa formação social do pensamento (diga-se assim por ora), que constitui a representação social, permite contatar o saber circulante acerca de objetos, assuntos, de uma ou sete cidades. Possibilita ainda detectar a existência de um senso comum e acessá-lo. Eis por que se considera tal referencial pertinente para a abordagem do problema antes detalhado.

Além disso, justifica-se pela demonstração da relevância da pesquisa das representações sociais, e da sua teoria referencial, para mais um campo de aplicação: o das cidades, e, de modo mais específico, as tombadas em nível mundial. Uma segunda justificativa traduz-se pelo empreendimento inovador aqui proposto: desvendar as representações sociais das cidades brasileiras patrimônio mundial, nas mais recentes das mídias, os websites. Trata-se de um trabalho interdisciplinar, envolvendo as áreas de Psicologia (onde surgiu a Teoria das Representações Sociais) e Comunicação (onde são estudadas as mídias eletrônicas). O terceiro motivo a justificar o estudo aqui proposto são os aportes que essas novas mídias podem trazer para os estudos urbanos.

Para atingir o objetivo colocado, o percurso contempla os seguintes fundamentos: os suportes narrativos de cidades, atentando para aqueles que precederam os sites; o patrimônio mundial, enfocando sua reprodutibilidade na cibercultura; a diversidade cultural, focalizando sua difusão na cibercultura; a teoria das representações sociais, demonstrando seus aportes para a pesquisa de cidades em mídias. Para o recorte dos sites, e para a detecção e análise das suas representações, foram aliados a tais fundamentos: os passos metodológicos sugeridos pela teoria das representações sociais e os métodos analíticodescritivos e de análise do discurso. Na construção metodológica é demonstrada a entrada da teoria das representações sociais na configuração da amostra de sites do objeto empírico, e no método para a análise dessa amostra.

Os aportes e constatações possibilitadas pelo percurso acima narrado permitem concluir pelo alcance do objetivo e demais conquistas do trabalho. Entre estas últimas, destaca-se a demonstração de que as representações sociais, sentidos e referências identificados na totalidade do recorte reforçam os critérios de inclusão na Lista do Patrimônio Mundial.

\section{Aportes da fundamentação teórica}

Neste tópico são sintetizados os aportes conquistados a partir dos fundamentos da tese que origina este artigo. O objetivo desta síntese é proporcionar uma visão geral da pesquisa e a contextualização dos aportes que embasam os procedimentos metodológicos da abordagem empírica. 
Figura 1: Reprodução da tela do mapa interativo do Sítio Histórico de Olinda. Fonte: BANDEPE. Disponível em: <http://www.culturalbandepe.com.br/mapa/igrejasolinda.htm>. Acesso em: 7 jun. 2006
Iniciando pela caracterização dos sites como os mais novos suportes narrativos das cidades comparativamente à arquitetura como espaço construído e aos livros e revistas, suportes que precederam os sites na narrativa de cidades. Os sites incorporaram algumas características de suportes que lhes precederam no tempo; entre essas, duas, sobretudo, se fazem mais notáveis. A primeira é a de ser um hipertexto, como o eram, antes dele, as obras de referência, tais como dicionários e atlas. A segunda é a de destacar elementos narrativos em janelas (Figura 1), como já faziam os antigos planisférios (Figura 2), algumas enciclopédias (Figura 3) e revistas (Figura 4).

Relativamente à arquitetura como espaço construído, em especial, os sites diferenciam-se, mormente, por não apresentarem os sentidos de abrigo e de pátina do tempo notados nessa. Entre os principais diferenciais dos sites relativamente aos suportes que Ihe precederam no tempo, os aspectos multimídias (textos, imagens, sons, filmes) e a interatividade podem ser apontados como os maiores deles. Para as cidades, essas características oferecem recursos de exposição multímoda desses espaços e, ao mesmo tempo, de interação entre várias cidades, e delas com os internautas, inclusive de modo simultâneo. Outras características específicas dos sites muito interessantes para as cidades são a rapidez e a amplitude de sua difusão na Web, encaminhando a síntese a seguir, que enfoca o patrimônio das cidades e sua reprodutibilidade na rede.

A reprodutibilidade dos monumentos e do patrimônio, por meio da difusão em sites da Web, concede-lhes gigantesca propagação (e consequente popularização). A Web, por sua rapidez em difundir informações sobre o patrimônio, o insere em novas temporalidades, propiciando-lhe novas formas de apropriação. A coletivização dos monumentos, miniaturizados por diferentes técnicas e difundidos na Web, não desfaz o encantamento da sua presença física, não concorrendo, assim, com a arquitetura, vista como uma realidade cuja efetuação é o espaço. A veiculação na Web amplia a partilhabilidade do patrimônio e pode promover a interação entre os sítios tombados, a produção coletiva de informações sobre esses sítios e aumentar a sociabilidade entre os seus moradores e internautas. Assim, pode também vir a contribuir para uma maior amplitude da difusão da Diversidade Cultural, o que se passa a relatar.

A Web, em sua ampla gama de mídias (sites, blogs, tags, entre outros ainda por surgir), é o meio fundamental para a difusão da diversidade cultural em sua pluralidade de expressões. A rede socializa a diversidade cultural e contribui para universalizar os documentos patrimoniais, no âmbito de toda a humanidade. Por tudo o que foi estudado sobre a diversidade cultural nos documentos da UNESCO, pode-se apontar a Web como meio

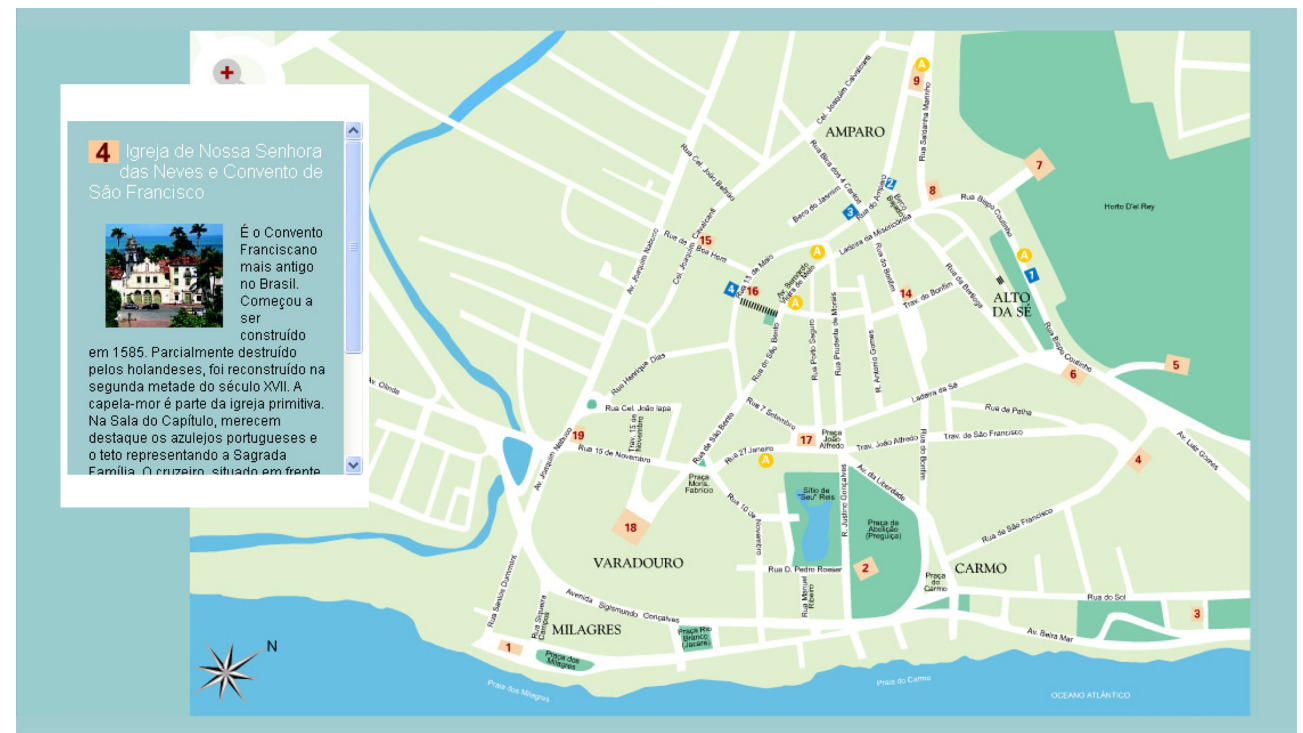



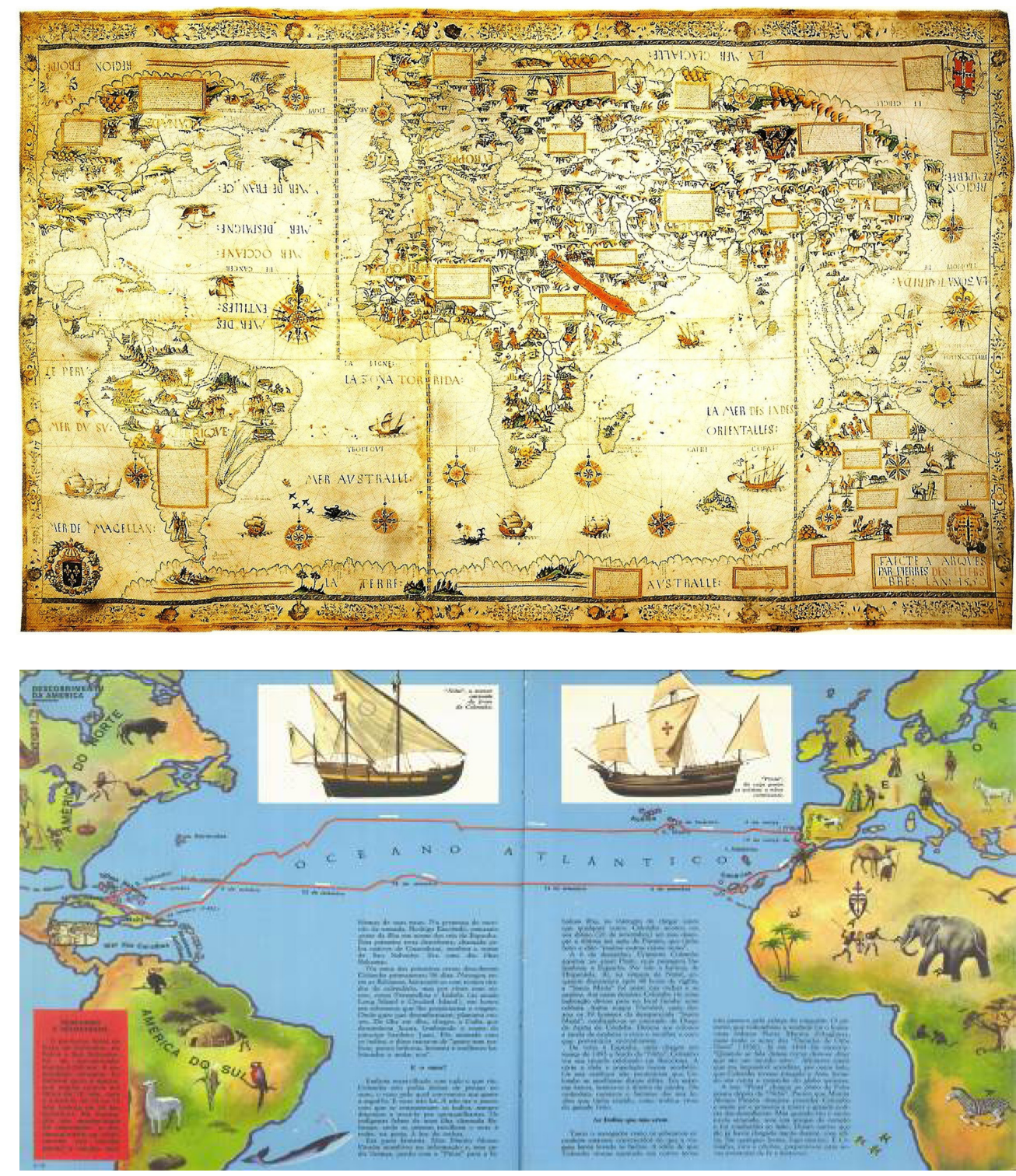

Figura 2: Reprodução do Planisphère, Arques, 1550 [Manuscrito iluminado sobre pergaminho]. Fonte: Descelliers (1550, apud BELLUZZO, 2000, p. 72).

Figura 3: Reprodução das páginas relativas ao verbete "América" na Enciclopédia Conhecer. Fonte: Enciclopédia (1972).

Figura 4: Reprodução das páginas 90 e 91 da matéria "Na Rota Histórica" (Revista Viagem e Turismo, maio 2006). Fonte: Camanho (apud DOLORES, 2006, p. 90-91).

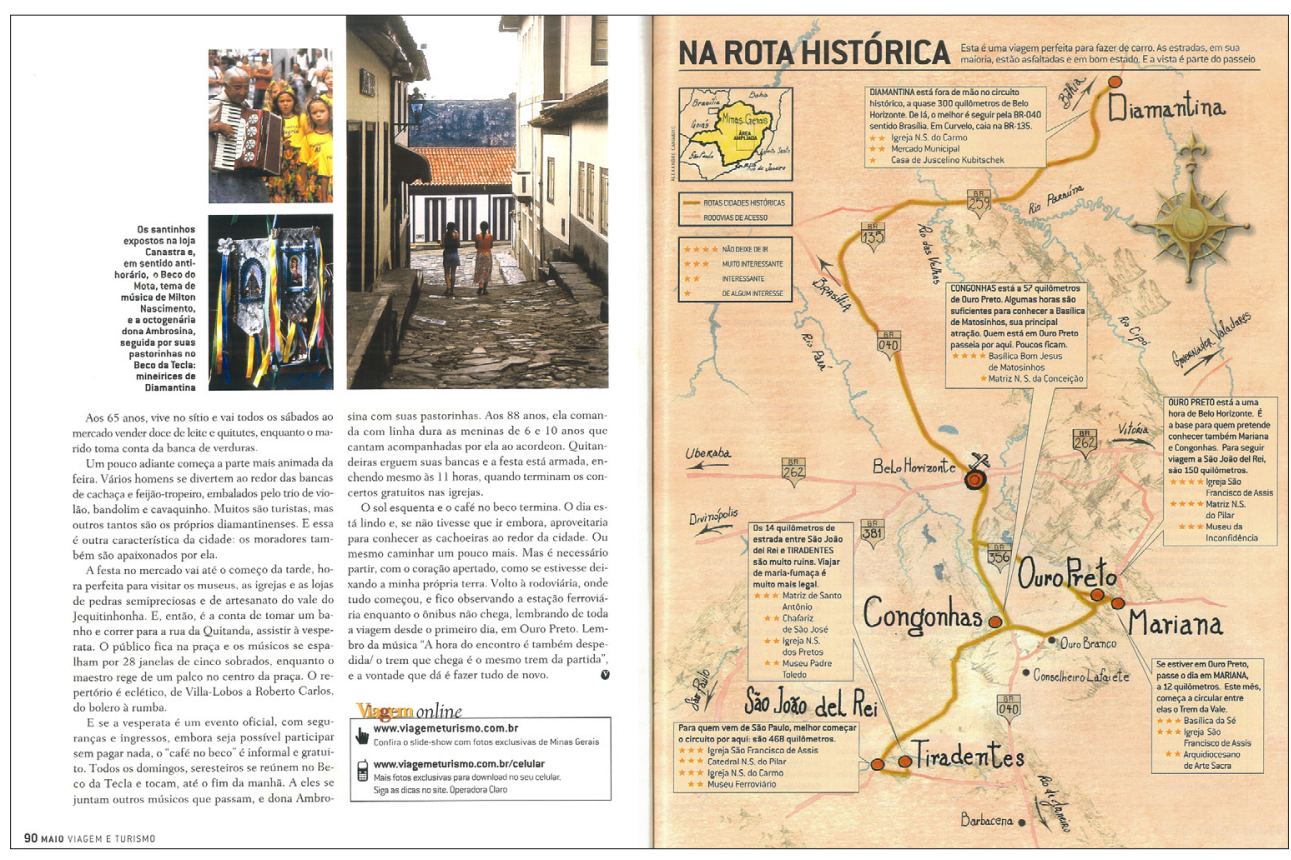


fundamental para a difusão da diversidade cultural e dos documentos patrimoniais nas novas configurações planetárias de tempo e escala.

Nesse ambiente multifário, multívago e universal da Web estão hoje inseridos o patrimônio mundial, seus conceitos, legislação, e as cidades tombadas. Eis o universo onde foram buscadas as representações sociais das cidades brasileiras patrimônio mundial, adentrando seus sites. Mas, antes de expor os resultados encontrados na pesquisa empírica, é preciso completar esta síntese das conquistas da fundamentação abordando a Teoria das Representações Sociais, com a qual os sites foram pesquisados e analisados.

A síntese do estudo da teoria adotada no trabalho enfocará aqui, especificamente, os passos metodológicos indicados por esse referencial teórico para a abordagem empírica. Dito isso, passa-se a sumarizar os principais pressupostos metodológicos que pautaram o estudo do objeto empírico. O primeiro foi justamente descartar o preestabelecimento de categorias, evitando induzir a detecção das representações sociais. Como ensina Moscovici (2004), são as próprias representações que, uma vez captadas, podem demarcar categorias, grupos.

O segundo é deixar falar os textos, sons e imagens, interpretando-os por algum método, no caso deste trabalho, pela análise do discurso, e arguindo-os para detectar, ali, a presença ou não de representações sociais. Neste ponto, vale lembrar como basicamente se explicita uma representação social, segundo Sá (1998, p. 68): em uma "[...] modalidade de saber gerada através da comunicação na vida cotidiana com a finalidade prática de orientar os comportamentos em situações sociais concretas [...]".

O terceiro pressuposto metodológico consiste em valorizar ao máximo possível uma base descritiva dos fenômenos de representação social captados nos sites, seguindo a orientação original da teoria por Moscovici. Ademais, ao estudar representações sociais, pode-se também encontrar elementos que gravitam em torno delas, sem que necessariamente formem um senso comum, ou mesmo consenso. Essa possibilidade endereça ao pressuposto seguinte.

O quarto pressuposto é a abertura à descoberta e posterior descrição, dos diversos elementos que gravitam em torno das representações sociais, e que podem ser por elas revelados, tais como sentidos e referências. Jodelet (2001) enfatiza a riqueza dos fenômenos de representação social, observando que eles facultam a descoberta de diversos elementos, entre os quais os assim designados pela psicóloga: "[...] informativos, cognitivos, ideológicos, normativos, crenças, valores, atitudes, opiniões, imagens [...]" (JODELET, 2001, p. 21).

O quinto pressuposto também é sinalizado por Jodelet (2001), ao alertar que o estudo das representações sociais deve articular elementos afetivos, mentais e sociais. Igualmente, que deve integrar "- ao lado da cognição, da linguagem e da comunicação - a consideração das relações sociais que afetam as representações e a realidade material, social e ideativa sobre a qual elas têm de intervir", acrescenta Jodelet (2001, p. 26). Vale notar que esse alerta enfatiza que as representações consideram o sujeito individualmente também, o que responde à crítica de que as representações igualam as pessoas sob um senso comum. Ou ainda, de que não existe senso comum, porque cada pessoa é um caso a ser analisado. Ora, dizer representação social, ou senso comum, não é necessariamente dizer consenso. Uma representação social é uma ideia-força, que pode, ou não, formar um senso comum; eis, aliás, um motivo para sua investigação.

Por fim, resta dizer que os fundamentos supracitados embasam igualmente a definição do recorte do estudo de caso. Em especial, vale notar que, também para este procedimento, não se pode partir de categorias preestabelecidas, o que se aplica a qualquer tipo de categorização (por exemplo: de natureza, de temática, etc.).

\section{Construção do objeto de pesquisa e método de análise da amostra de sites}

Consoante o objetivo do trabalho, e com base nos fundamentos e pressupostos metodológicos anteriormente apresentados, os procedimentos adotados especificamente na construção do objeto de pesquisa foram os seguintes:

1. Observação livre para um primeiro conhecimento do universo de sites, visando à análise prévia de que trata o próximo passo. Para esta observação, 
que começou junto com o trabalho, desde a sua fase de projeto, foram feitas pesquisas com entradas e datas aleatórias, em um mesmo site de buscas.

2. Análise prévia do conteúdo dos sites assim obtidos, visando avaliar sua pertinência como objeto de pesquisa das representações sociais. $\mathrm{O}$ método adotado na análise prévia foi o analítico descritivo, descartando o preestabelecimento de categorias, evitando induzir a detecção das representações sociais.

3. Pesquisas sistemáticas visando à configuração de um recorte para o estudo de caso. Foram feitas sete pesquisas em um mesmo site de buscas, em diferentes datas, e com diferentes entradas, obtendo um total de 215 sites.

4. Análise de conteúdo desses 215 sites, pelo método analítico descritivo, contemplando seus recursos multimídias (textos imagens, sons, animações, etc.), para embasar os critérios de configuração do recorte.

5. Configuração de um recorte para o estudo de caso, mediante o cruzamento dos resultados das sete pesquisas realizadas em um mesmo site de buscas. As sete pesquisas foram feitas em diferentes datas, e com diferentes entradas. Elas permitiram delinear um recorte composto por um total de 28 sites, sendo quatro sites para cada uma das sete cidades.

Todos esses procedimentos foram acompanhados - e intercalados - por dois outros procedimentos fundamentais para a construção do objeto de pesquisa: (i) uma ampla pesquisa bibliográfica sobre a história de cada uma das sete cidades, considerando que as representações sociais são processos socialmente construídos ao longo da história; (ii) visitas a todas as sete cidades, apesar de a autora já conhecer, à época da tese, seis delas - a única de que não se tinha conhecimento prévio era São Luís. Passa-se agora à apresentação do método.

No que se refere ao método, conforme Sá (1998), a pesquisa em representações sociais deve iniciarse por uma observação do fenômeno que se quer estudar, para verificar a pertinência de seu estudo como representação social. Foi por seguir tal orientação que o método da investigação empírica e, mais especificamente, da análise dos sites da amostra iniciou-se por uma leitura desses sites. Esse passo, no caminho maior que é o método, está totalmente de acordo com a teoria moscoviciana e afina-se com o seu principal conceito, o de senso comum. Isso se justifica pelo fato de que a leitura é uma atividade imbuída das próprias experiências do leitor, significações e senso comum. Como explica Manguel (2001 p. 53), "[...] ao seguir o texto, o leitor pronuncia seu sentido por meio de um método profundamente emaranhado de significações aprendidas, convenções sociais, leituras anteriores, experiências individuais e gosto pessoal." Com base nessas reflexões e nos fundamentos expostos na síntese da fundamentação teórica, formou-se o método para a análise da amostra de sites. O método compreende os seguintes procedimentos:

1. Detecção das representações sociais e/ou sentidos prevalentes em cada um dos quatro sites de cada cidade, pela análise de seu conteúdo, a qual adota o método de análise do discurso. Este procedimento permite obter as representações, ou sentidos prevalentes, de cada site, especificamente, para uma dada cidade.

2. Cotejamento dessas representações sociais e/ ou sentidos prevalentes de cada site com a dos outros sites formadores do conjunto de quatro sites (respeitantes a uma mesma cidade). Este procedimento permite detectar se há ou não consenso entre representações sociais do conjunto de quatro sites para uma mesma cidade, ou senso comum nesse conjunto.

3. Análise comparada das representações e/ou sentidos (detectados no procedimento anterior) relativamente aos critérios de inscrição da cidade na Lista do Patrimônio Mundial. Este procedimento permite avaliar se tais representações e/ou sentidos se refletem em tais critérios, se os corroboram ou reforçam.

4. Cotejamento das representações sociais dos 28 sites (obtidas pelos dois passos precedentes) para avaliar se, dentro desse conjunto maior, há representações afins, próximas, ou que possam compor grupos de mesma natureza. 
Na possibilidade de formar grupos de mesma natureza, estes poderão ser tomados como base da gênese dos fenômenos de representação social. (Tal pensamento apoia-se na formulação original da teoria de Moscovici, quanto à busca da gênese das representações sociais.)

5. Análise conjunta das representações e de seus grupos (relatada no procedimento anterior), refletindo se são passíveis de participar da formação de um senso comum acerca da cidade patrimônio mundial no Brasil. Este procedimento permite comprovar ou negar a existência de tal senso comum e fornece dados para o procedimento seguinte.

6. Análise comparada desses grupos de mesma natureza para avaliar se podem compor um grupo que valide a totalidade dos critérios de inclusão das cidades na Lista do Patrimônio Mundial.

Três observações são importantes sobre a condução deste método. A primeira é que, embora se tenha notado que muitos trabalhos de representações sociais optem por enunciar os sentidos em torno de seus objetos, em lugar de declarar as suas representações, na tese optou-se por evidenciálas, sempre que se apresentem. A segunda concerne à fundamentação do método da análise do discurso. Para embasá-lo, foram pesquisados autores referenciais e convocados dicionários diretamente dedicados ao método, ou a ele respeitantes: Charaudeau e Maingueneau (2006); Moisés (2002); Lalande (1999). Para subsidiar a teoria das representações sociais na análise das imagens especificamente, contou-se com os referenciais de Bachelard (1988, 1990, 1998, 1999, 2001), e Barthes (1984). A terceira refere-se aos sentidos detectados. Para alcançá-los em seus significados correntes, recorreu-se a dicionários de português, considerando o caráter de saber incorporado ao cotidiano, caráter este que participa das representações sociais e dos sentidos a elas associados. Explicado o método, segue-se por expor algumas notas sobre a análise.

A análise limita-se às páginas do site, não abarcando os links para outros sites neles contidos. Em todas as apresentações dos resultados obtidos por cidade são citados os critérios segundo os quais as cidades foram tombadas na instância mundial. A lista de critérios, constante da Convenção sobre a Proteção do Patrimônio Mundial Cultural e Natural, tratado internacional aprovado em 1972, é a abaixo transcrita.

Os bens culturais devem:

I. Representar uma obra-prima do gênio criativo humano, ou

II. Ser a manifestação de um intercâmbio considerável de valores humanos durante um determinado período ou em uma área cultural específica, no desenvolvimento da arquitetura, das artes monumentais, de planejamento urbano ou do desenho da paisagem, ou

III. Aportar um testemunho único ou pelo menos excepcional de uma tradição cultural ou de uma civilização que continue viva ou que tenha desaparecido, ou

IV. Ser um exemplo excepcional de um tipo de edifício ou de conjunto arquitetônico ou tecnológico, ou de paisagem que ilustre uma ou várias etapas significativas da história da humanidade, ou

\section{Constituir um exemplo excepcional de habitat ou} estabelecimento humano tradicional ou do uso da terra, que seja representativo de uma cultura ou de culturas, especialmente as que se tenham tornado vulneráveis por efeitos de mudanças irreversíveis, ou

VI. Estar associados diretamente ou tangivelmente a acontecimentos ou tradições vivas, com idéias ou crenças, ou com obras artísticas ou literárias de significado universal excepcional (O comitê considera que este critério não deveria justificar a inscrição na Lista, salvo em circunstâncias excepcionais e na aplicação conjunta com outros critérios culturais ou naturais).

É igualmente importante o critério da autenticidade do sítio e a forma pela qual esteja protegido e administrado (UNESCO, 2004, p. 290).

A análise é iniciada pelo primeiro procedimento (detecção das representações sociais em cada site). Como a análise contempla 28 sites e é bem extensa, neste artigo optou-se por relatar apenas 
os resultados nela obtidos, objeto do próximo tópico.

\section{Representações sociais prevalentes de cada site em face dos demais}

Neste tópico, cumpre-se o segundo e o terceiro procedimentos do método. Começase por rememorar os sentidos e representações encontrados no conjunto de quatro sites para Ouro Preto: site Cidade de Ouro Preto - representação social: turismo de massa; site Ouro Preto - sentido prevalente: permanência; site Cidades Históricas Brasileiras/Ouro Preto - representação social: cultura; site Idas Brasil/Ouro Preto - representação social: passado.

Pelos sentidos e representações expostos acima, pode-se assinalar no conjunto dois pares: um primeiro, de afinidade; um segundo, de incompatibilidade. O primeiro é formado pelo site Ouro Preto (sentido de permanência) e o site Idas Brasil (representação social de passado). Permanência é o ato de permanecer, verbo que correntemente significa: "[...] continuar sendo; prosseguir existindo; conservar-se, ficar [...]", segundo Houaiss (2001). Portanto, permanência é um sentido que denota o passado, podendo ser encampado por sua representação social.

O segundo par, o de incompatibilidades, é formado pelo site Cidade de Ouro Preto, (representação social de turismo de massa) e o site Cidades Históricas Brasileiras/Ouro Preto (representação social de cultura). O turismo de massa pode ser entendido como uma manifestação da cultura de massa, que tem uma conotação altamente comercial. Muito diferente, portanto, da representação social detectada no site Cidades Históricas Brasileiras/Ouro Preto, onde a cultura assoma como elevação. Para maior clareza, são repetidas a seguir as acepções de cultura no contexto deste último site: "[...] o cabedal de conhecimentos, a ilustração, o saber de uma pessoa ou grupo social [...]", conforme Houaiss (2001).

Diante dessas reflexões, não se pode concluir pela existência de um consenso neste conjunto de quatro sites para Ouro Preto. Tais pensamentos tampouco autorizam a detectar ali um senso comum. Não se detecta em sua acepção corrente, segundo Houaiss
(2001), como conjunto de idéias prevalecentes no contexto social. Tampouco assoma ali, nos termos de Moscovici (2004, p. 134), como "[...] um produto da cultura, que, em nossa sociedade, é mesclado com teorias científicas [...]".

Por fim, cabem algumas considerações sobre tais sentidos e representações relativamente aos critérios com que a cidade foi incluída na Lista do Patrimônio Mundial. Começa-se por repetir tais critérios, para maior clareza da pertinência das considerações que serão adiante expressadas.

I. Representar uma obra-prima do gênio criativo humano, ou $[\ldots]$

III. Aportar um testemunho único ou pelo menos excepcional de uma tradição cultural ou de uma civilização que continue viva ou que tenha desaparecido, ou [...] (UNESCO, 2004, p. 290).

Nesse âmbito, pode-se considerar que o sentido de permanência e a representação social de passado reforçam diretamente ambos os critérios. Fazemno por repercutirem no tempo a obra do "gênio criativo humano", bem como por reforçarem as idéias de continuidade, tradição e civilização. Do mesmo modo, a representação social de cultura reforça esses critérios. Ao primeiro, por estar implícita na cultura a noção de obra-prima, sendo inclusive tal significado de exemplaridade acionado no site Cidades Históricas Brasileiras/Ouro Preto. Ao terceiro por ser a representação social de cultura participante das idéias de tradição cultural e civilização. Neste sentido, a representação social de cultura, além de ser estruturante dessas idéias, liga-se ao sentido de continuidade dessas noções. Por tudo isso, reflete-se que o sentido de permanência e as representações sociais de cultura e de passado concorrem para legitimar tais critérios e, por conseguinte, o tombamento mundial da cidade.

Para Olinda, os sentidos e representações encontrados no conjunto de quatro sites são os seguintes: site da Prefeitura de Municipal de Olinda - representação social: cultura popular; site Olinda Virtual - sentido prevalente: pluralidade; site Olinda Online - representação social: ócio (observação: este site não cita o título de patrimônio mundial de Olinda); site do Albergue de Olinda - representação social: cultura. 
No conjunto acima, identifica-se um par de proximidades de representações, entre as representações sociais de cultura popular (site da Prefeitura Municipal de Olinda) e de cultura (site do Albergue de Olinda). Reflete-se que a representação social de cultura no site do Albergue de Olinda, por ser mais abrangente, inclusive por abarcar manifestações da cultura popular (o carnaval, as festividades, etc.), sobressai como representação mais forte da cidade. Quanto aos sentidos de pluralidade e de ócio, dos outros dois sites, entendese que eles não manifestam proximidade entre si, sendo, ao contrário, bastante diferentes. No entanto, o fato de serem tão diferentes reforça o sentido de pluralidade para a cidade. Do mesmo modo, pondera-se que, consideradas as representações sociais de cultura popular e de cultura, em sua diferenciação do sentido de ócio, o sentido de pluralidade novamente sai fortalecido, já que é indicativo dessa diferença. Tais pensamentos não autorizam a concluir pela existência, nesse conjunto, de um senso comum para Olinda. Passa-se agora a refletir sobre tal conjunto em face dos critérios de tombamento mundial da cidade, os quais são repetidos abaixo:

II. Ser a manifestação de um intercâmbio considerável de valores humanos durante um determinado período ou em uma área cultural específica, no desenvolvimento da arquitetura, das artes monumentais, de planejamento urbano ou do desenho da paisagem, ou [...]

IV. Ser um exemplo excepcional de um tipo de edifício ou de conjunto arquitetônico ou tecnológico, ou de paisagem que ilustre uma ou várias etapas significativas da história da humanidade, ou [...] (UNESCO, 2004, p. 290).

Diante dos teores dos critérios acima, reflete-se que as representações sociais de cultura e de cultura popular os reforçam e legitimam. Do mesmo modo, pode-se considerar que o sentido de pluralidade o faz, na medida em que tal sentido pode ser ali detectado pelas idéias de intercâmbio e de variedade de etapas significativas da história.

Segue-se agora para análise dos sentidos e representações encontrados no conjunto de sites para Salvador. O conjunto de quatro sites para Salvador revelou as seguintes representações sociais: site da Empresa de Turismo de Salvador - representações sociais: capital e miscigenação; site Visite a Bahia - representação social: força; site Bahia - representação social: turismo; site Brasil Viagem/Salvador - representação social: paisagem.

São, portanto, cinco representações, bastante diferentes entre si, embora algumas delas possam acionar idéias que formam as outras. Por exemplo, a representação social de força, no site Visite a Bahia, acionou a idéia de miscigenação como um fator que contribui para a força da culinária local. A representação social de paisagem, no site Brasil Viagem/Salvador, associa-se à noção de turismo. No entanto, em seu todo, o que o conjunto acima expresso permite depreender é a diversidade de representações para a cidade. Não autoriza, este todo, a identificação de consenso, tampouco de senso comum para Salvador. Feitas essas reflexões, passa-se a analisar tais representações relativamente aos critérios pelos quais a cidade foi tombada, rememorados a seguir:

IV. Ser um exemplo excepcional de um tipo de edifício ou de conjunto arquitetônico ou tecnológico, ou de paisagem que ilustre uma ou várias etapas significativas da história da humanidade, ou [...]

VI. Estar associados diretamente ou tangivelmente a acontecimentos ou tradições vivas, com idéias ou crenças, ou com obras artísticas ou literárias de significado universal excepcional (O comitê considera que este critério não deveria justificar a inscrição na Lista, salvo em circunstâncias excepcionais e na aplicação conjunta com outros critérios culturais ou naturais) [...] (UNESCO, 2004, p. 290)

Pode-se considerar que a representação social de paisagem valoriza o critério IV, por poder ser entendida como uma síntese espacial e temporal de todos os elementos ali citados. A representação social de miscigenação parece reforçar o critério VI, por associar-se, nos sites onde surgiu, às tradições, ideias, crenças e obras da criatividade humana. Já as representações sociais de capital, força e turismo não parecem passíveis de reforçar, tampouco de repercutir diretamente os dois critérios supracitados. 
Passa-se agora às reflexões sobre o conjunto de sites de Brasilia, que revelou as representações sociais citadas a seguir: site A Cidade de Brasília - representação social: cidade; site Brasília Patrimônio Cultural da Humanidade - representação social: conhecimento; site Brasília Convention - sentido: extraordinário; site Guia de Brasília - representação social: arquitetura.

São, portanto, três representações e um sentido bem diferentes entre si, embora se possa identificar um par de proximidades entre as representações sociais de cidade e arquitetura. Essa proximidade se justifica pelo fato de a cidade, ela mesma, poder ser entendida como uma arquitetura. Assim a entendem alguns autores referenciais de arquitetura e urbanismo, entre eles, Aldo Rossi (1998), que defende esta idéia em seu livro Arquitetura da Cidade. Tal proximidade igualmente se justifica no recorte de sites de Brasília, uma vez que, no site A Cidade de Brasília, o sentido de arquitetura é amplamente acionado pela representação social de cidade. Do mesmo modo, no site Guia de Brasília, a idéia de cidade é alavancada pela representação social de arquitetura.

Mesmo com tal par de proximidades, não se pode, no entanto, considerar a existência de um consenso no conjunto formado pelos quatro sites, tampouco de um senso comum. A propósito, vale notar o quão diferentes entre si são a representação social de conhecimento e o sentido de extraordinário. A cidade vista como conhecimento, no site Brasília Patrimônio Cultural da Humanidade, em nada diminui a sua notabilidade. Este significado é ali repassado, integra o conhecimento da cidade, sendo inclusive fundamentado por sua arquitetura e urbanismo, por sua condição de capital projetada e edificada segundo cânones modernistas. No entanto, não é a cidade ali instruída pela idéia de extraordinário, e o site não aciona este sentido em sua representação social de conhecimento para a cidade. Tampouco o site Brasília Convention, que entende e repassa a cidade segundo o sentido de extraordinário, aciona, para tanto, o sentido de conhecimento.

Ponderada a impossibilidade do consenso e a não pertinência do senso comum, no conjunto dos sites para Brasília, passa-se a discutir esta totalidade relativamente ao seu tombamento, que se deu segundo os seguintes critérios:
I. Representar uma obra-prima do gênio criativo humano, ou [...]

IV. Ser um exemplo excepcional de um tipo de edifício ou de conjunto arquitetônico ou tecnológico, ou de paisagem que ilustre uma ou várias etapas significativas da história da humanidade, ou [...] (UNESCO, 2004, p. 290).

Tendo em vista tais critérios, pode-se considerar que todas as representações sociais detectadas os repercutem e validam. As representações sociais de cidade e arquitetura reforçam claramente as noções de "obra-prima do gênio criativo humano" e de edifício, conjunto e paisagem, ilustrativos de etapas históricas significativas, acima expressas. Igualmente, o sentido de extraordinário fortalece as noções de obra-prima e de excepcionalidade. Por fim, a representação social de conhecimento, implicando o gênio e a ação humana, que o constroem, reforça ambos os critérios.

Doravante, segue-se para o conjunto dos quatro sites de São Luís, que revelou o que segue: site Cidades Históricas Brasileiras/São Luís - referência: interação cultural; site Patrimônio da Humanidade - representação social: estética; site Brasil Viagem/ São Luís - representação social: misticismo; site Governo do Estado do Maranhão - representação social: europeísmo.

Nos resultados assim reunidos, encontra-se um par de afinidades entre a referência de interação cultural e a representação social de europeísmo, uma vez que esta última se vincula aos povos brancos partícipes da referência de interação cultural. Outra afinidade possível se manifesta entre as representações sociais de estética e europeísmo. Isso porque, em ambas, são acionados, nos seus respectivos sites, os dados culturais europeus (franceses, holandeses, portugueses, e atenienses) e, em especial, a lusotropicologia. Uma terceira associação possível dá-se entre a representação social de misticismo e a referência de interação cultural. Essa associação se justifica pela assimilação, no misticismo, dos elementos folclóricos e religiosos das raças brancas, negras e indígenas, que constroem a referência de interação cultural. Diante disso, pode-se refletir que as representações sociais de europeísmo e de misticismo despontam com mais força no conjunto. 
Tais resultados são vistos agora relativamente aos critérios de inclusão de São Luís na lista da UNESCO, que são os seguintes:

III. Aportar um testemunho único ou pelo menos excepcional de uma tradição cultural ou de uma civilização que continue viva ou que tenha desaparecido, ou

IV. Ser um exemplo excepcional de um tipo de edifício ou de conjunto arquitetônico ou tecnológico, ou de paisagem que ilustre uma ou várias etapas significativas da história da humanidade, ou

V. Constituir um exemplo excepcional de habitat ou estabelecimento humano tradicional ou do uso da terra, que seja representativo de uma cultura ou de culturas, especialmente as que se tenham tornado vulneráveis por efeitos de mudanças irreversíveis, ou [...] (UNESCO, 2004, p. 290).

A referência de interação cultural e as representações sociais de misticismo e europeísmo reforçam o critério III. A representação social de estética, sozinha, por sua vez, reforça diretamente o IV critério e, associada à referência de interação cultural e à representação social de europeísmo, enfatiza o critério V. No cômputo geral, portanto, é possível avaliar que todo este conjunto corrobora os critérios de tombamento da cidade, concorrendo, assim, para legitimá-los.

Ainda sobre o conjunto de sites de São Luís, vale notar que, em dois deles, são encontradas referências ao sentido de modernidade. No site Patrimônio da Humanidade (2008), a modernidade é ligada à luminosidade e colocada de modo aditivo à antiguidade, manifesta nesta passagem: “Envolvida na melodia de suas muitas vozes, São Luís é toda ela memória e poesia. E é também luz. Luzes. Prédios altos, shoppings, largas avenidas, danceterias, bares, restaurantes [...]" (PATRIMÔNIO da Humanidade, 2008). No site Brasil Viagem/São Luís (2008), a modernidade surge na descrição comparativa de pólos da cidade, a seguir: "Com suas ruas de pedra, seus becos de cantaria, sobrados de azulejos, praias de areias brancas e edifícios de arquitetura moderna que servem de contraponto, a cidade é acostumada a dividir-se entre o passado, presente e futuro". Em ambos os contextos de surgimento, o sentido de modernidade não desmerece a inclusão da cidade na Lista do Patrimônio Mundial, tampouco os critérios pelos quais se deu sua inclusão. Não obstante, considera-se digna de ressaltar a presença do sentido pelo modo de contraposição com que se manifesta nos dois casos: como se fora uma compensação à antiguidade da cidade.

Segue-se agora para a reflexão sobre o conjunto de sites de Diamantina, que revelou as seguintes representações sociais: site Diamantina.com.br representação social: turismo; site Cidades Históricas Brasileiras/Diamantina - representação social: abrigo; site Idas Brasil/Diamantina - representação social: diamante; site Descubra Minas - representação social: tradição.

São quatro representações sociais bastante diferentes entre si, não permitindo sequer uma aproximação entre umas e outras. Vale lembrar que esses quatro sites de Diamantina podem ser relacionados de alguma forma ao turismo, por exporem a cidade em sua atratividade. Essa afinidade de escopos torna a constatação da diversidade de representações digna de causar espécie, por demonstrar que tal afinidade de objetivos não implica necessariamente proximidade ou semelhança de representações sociais. Isso posto, passa-se para a avaliação dessas representações relativamente ao tombamento mundial da cidade. Diamantina teve sua inclusão na Lista do Patrimônio Mundial pelos critérios abaixo relembrados:

II. Ser a manifestação de um intercâmbio considerável de valores humanos durante um determinado período ou em uma área cultural específica, no desenvolvimento da arquitetura, das artes monumentais, de planejamento urbano ou do desenho da paisagem, ou [...]

IV. Ser um exemplo excepcional de um tipo de edifício ou de conjunto arquitetônico ou tecnológico, ou de paisagem que ilustre uma ou várias etapas significativas da história da humanidade, ou [...] (UNESCO, 2004, p. 290).

Considerados os teores de continuidade e permanência contidos nos dois critérios, pode-se concluir que a representação social de tradição reforça a ambos, concorrendo para legitimá-los. Na visão deste trabalho, a representação social de abrigo igualmente os reforça, porque, tal como surge no site, revela tanto o desenvolvimento da 
arquitetura, por ser a cidade ali entendida como uma arquitetura que abriga, quanto a paisagem, citada no critério IV. No caso desta última, vale lembrar que o entorno paisagístico da cidade, com suas grutas, foi codificado no site pela representação social de abrigo. As demais representações, se não reforçam os dois critérios, ao menos repercutem a história da cidade, no caso da representação social do diamante. Ou ainda, agregam sentidos positivos à cidade, no caso da representação social de turismo, ao remeter à viagem, ao lazer, ao desfrute do tempo livre.

Finda-se pelo conjunto de sites para Goiás Velho, onde foram encontradas as seguintes representações sociais: site Vila Boa de Goiás - representação social: comércio; site Altiplano - representação social: poder; site Cidades Históricas Brasileiras - representação social: província; site Brazil on Board - representação social: cultura. São quatro representações sociais bastante diferentes, que não autorizam a considerar qualquer espécie de afinidade entre si. Assim, o conjunto permite refletir pela diversidade absoluta de representações nesta totalidade e descartar a possibilidade de um consenso. Autoriza, também, a ponderar que as duas primeiras representações parecem ligar-se ao jogo de interesses que caracteriza historicamente as cidades e que as duas últimas refletem percepções da cidade mais ligadas a visões antropológicas e estéticas. Doravante passa-se a refletir sobre tais representações sociais relativamente aos critérios pelos quais a cidade foi incluída na Lista do Patrimônio Mundial. Assim como Olinda e Diamantina, Goiás Velho foi tombado na instância mundial pelos critérios II e IV.

II. Ser a manifestação de um intercâmbio considerável de valores humanos durante um determinado período ou em uma área cultural específica, no desenvolvimento da arquitetura, das artes monumentais, de planejamento urbano ou do desenho da paisagem, ou [...]

IV. Ser um exemplo excepcional de um tipo de edifício ou de conjunto arquitetônico ou tecnológico, ou de paisagem que ilustre uma ou várias etapas significativas da história da humanidade, ou [...] (UNESCO, 2004, p. 290).

Diante de tais teores, que contemplam intercâmbio de valores, produções culturais e historicidade, a representação social de cultura evidencia-se como a única que pode ser imediatamente vinculada aos dois critérios. A representação social de província, ligada a locais como a Provence na França, e a Toscana na Itália, em sua internacionalidade e atemporalidade, parece, no entanto, cumprir o desígnio de paisagem ilustrativa, contido no critério IV. Além disso, pode-se refletir que a representação social de província repercute o intercâmbio de valores humanos, refletido no desenho de paisagem, no caso de Goiás Velho, da paisagem provinciana ali perpetuada. Desse modo, ao repercutir o teor citado no critério II, a representação social de província concorre para reforçá-lo. Assim sendo, considera-se que tanto a representação social de cultura, quanto a de província, ao corroborarem os critérios de tombamento da cidade, contribuem para legitimá-los.

Sendo esta a sétima cidade, encerram-se aqui os segundo e terceiro procedimentos metodológicos, que permitiram alcançar as reflexões já detalhadas, cujas principais constatações são doravante sumarizadas. A primeira é a inexistência de consenso ou de senso comum entre representações sociais e sentidos prevalentes em todos os conjuntos de quatro sites para uma mesma cidade. A segunda é a de que, em todos os conjuntos de quatro sites, há representações sociais e sentidos prevalentes que corroboram os critérios de tombamento da cidade a que correspondem. A terceira é a de que, para as cidades de Brasília e São Luís, todas as representações e sentidos obtidos reforçam os critérios de seus tombamentos na instância mundial.

\section{Cotejamento e reflexões sobre as representações sociais na totalidade dos sites}

Neste tópico, cumprem-se o quarto, o quinto e o sexto procedimentos do método. Iniciase por enumerar os 28 sites e suas respectivas representações e sentidos, assinalando com uma mesma cor as representações que se repetem nessa totalidade (Tabela 1).

Como pode ser visto, as únicas representações sociais que aparecem mais de uma vez na totalidade dos 28 sites são as de cultura, com três aparições, e de turismo, com duas. Assim sendo, não se pode concluir pela existência de consenso ou de senso comum para a cidade patrimônio mundial 


\begin{tabular}{|c|c|}
\hline Site & Resultados encontrados \\
\hline 1. Site Cidade de Ouro Preto & Representação social: turismo de massa. \\
\hline 2. Site Ouro Preto & Sentido prevalente: permanência \\
\hline 3. Site Cidades Históricas Brasileiras/Ouro Preto & Representação social: cultura \\
\hline 4. Site Idas Brasil/Ouro Preto & Representação social: passado \\
\hline 5. Site da Prefeitura de Municipal de Olinda & Representação social: cultura popular \\
\hline 6. Site Olinda Virtual & Sentido prevalente: pluralidade \\
\hline 7. Site Olinda Online & Representação social: ócio \\
\hline 8. Site do Albergue de Olinda & Representação social: cultura. \\
\hline 9. Site da Empresa de Turismo de Salvador & Representações sociais: capital e miscigenação \\
\hline 10. Site Visite a Bahia & Representação social: força \\
\hline 11. Site Bahia (bahia.com.br) & Representação social: turismo \\
\hline 12. Site Brasil Viagem/Salvador & Representação social: paisagem \\
\hline 13. Site A Cidade de Brasília & Representação social: cidade \\
\hline 14. Site Brasília Patrimônio Cultural da Humanidade & Representação social: conhecimento \\
\hline 15. Site Brasília Convention & Sentido prevalente: extraordinário \\
\hline 16. Site Guia de Brasília & Representação social: arquitetura \\
\hline 17. Site Cidades Históricas Brasileiras/São Luís & Referência: interação cultural \\
\hline 18. Site Patrimônio da Humanidade & Representação social: estética \\
\hline 19. Site Brasil Viagem/São Luís & Representação social: misticismo \\
\hline 20. Site Governo do Estado do Maranhão & Representação social: europeísmo \\
\hline 21. Site Diamantina.com.br & Representação social: turismo \\
\hline 22. Site Cidades Históricas Brasileiras & Representação social: abrigo \\
\hline 23. Site Idas Brasil/Diamantina & Representação social: diamante \\
\hline 24. Site Descubra Minas/Diamantina & Representação social: tradição \\
\hline 25. Site Vila Boa de Goiás & Representação social: comércio \\
\hline 26. Site Altiplano & Representação social: poder \\
\hline 27. Site Cidades Históricas Brasileiras & Representação social: província \\
\hline 28. Site Brazil on Board & Representação social: cultura \\
\hline
\end{tabular}

Figura 5: Tabela 1, Totalidade de sites e respectivos resultados. na totalidade do recorte. Vale lembrar que a inexistência de consenso e de senso comum já fora antes notada nos conjuntos de quatro sites por cidade. Essa inexistência de consenso e de senso comum nos conjuntos de quatro sites e na totalidade de 28 sites manifesta, no entender deste trabalho, a diversidade cultural como patrimônio no âmbito da Web.

Na totalidade dos sites, constata-se ainda que quatorze representações sociais, três sentidos e a referência de interação reforçam os critérios de inserção de suas cidades na lista do patrimônio mundial. As quatorze representações sociais são as que seguem: passado, cultura, cultura popular, paisagem, miscigenação, cidade, arquitetura, conhecimento, misticismo, europeísmo, estética, tradição, abrigo, província. Os três sentidos são os de permanência, pluralidade e extraordinário. A referência é a de interação cultural. Entre as representações, sentidos e referência obtidos na totalidade dos 28 sites, pode-se, ainda, identificar proximidades e afinidades entre resultados de diferentes cidades, permitindo formar grupos de naturezas afins. Os agrupamentos são ditados pela semelhança de natureza conceitual entre as representações sociais, sentidos e referência, considerando a pertinência de cada qual em apenas um grupo. Consoante tais critérios, foram identificados os grupos detalhados na Tabela 2.

Somente duas representações e um sentido não pareceram pertinentes a nenhum dos oito grupos acima: as representações sociais de ócio e comércio e o sentido de pluralidade. Tendo em vista a identificação daqueles oito grupos diferentes e também dessas representações e sentidos que não os integram, mais uma vez, confirma-se a inexistência de um consenso entre os 28 sites. É igualmente 


\begin{tabular}{|l|l|}
\hline Grupos & Representações / sentidos / referências \\
\hline 1. Grupo de Espaço & Representações sociais: abrigo e arquitetura \\
\hline 2. Grupo de Tempo & $\begin{array}{l}\text { Representações sociais: passa do, tradição/ sentido de } \\
\text { permanência }\end{array}$ \\
\hline 3. Grupo de Cultura & $\begin{array}{l}\text { Representações sociais: cultura, cultura popular, } \\
\text { conhecimento, misticismo/referência de interação } \\
\text { cultural }\end{array}$ \\
\hline 4. Grupo de Territorialidades Urbanas & Representações sociais: capital, cidade, província \\
\hline 5. Grupo de Poder & Representações sociais: poder e força \\
\hline 6. Grupo de Turismo & Representações sociais: turismo e turismo de massa \\
\hline 7. Grupo de Estética & $\begin{array}{l}\text { Representações sociais: estética, diamante, } \\
\text { paisagem/sentido de extraordinário. }\end{array}$ \\
\hline 8. Grupo de Etnias & Representações sociais: miscigenação e europeísmo \\
\hline
\end{tabular}

Figura 6: Tabela 2, Grupos de naturezas afins.

2 No original: // faut, pour qu'il ait du patrimoine reconnaissable, gérable, qu'une société se saisisse en miroir d'elle-même [...] conclusiva para este trabalho a inexistência de um senso comum para a cidade brasileira patrimônio mundial. No entender desta autora, isso mostra que, no caso brasileiro, a diversidade cultural, manifesta internamente no país, reflete-se também no contexto da Web. No entanto, consideradas as naturezas que presidem tais grupos, pondera-se ainda que os próprios grupos, por si sós, podem vir a reforçar os critérios de tombamento. Para checar a pertinência dessa ponderação, doravante passa-se ao sexto procedimento. Este consiste em avaliar se os grupos de mesma natureza podem compor um conjunto que valide a totalidade dos critérios de inclusão das cidades na Lista do Patrimônio Mundial.

Diante da totalidade dos critérios, os grupos de mesma natureza que parecem reforçá-los inteiramente são os seguintes: grupo de espaço (representações sociais: abrigo e arquitetura); grupo de tempo (representações sociais: passado, tradição; sentido de permanência); grupo de cultura (representações sociais: cultura, cultura popular, conhecimento, misticismo; referência de interação cultural); grupo de territorialidades urbanas (representações sociais: capital, cidade, província); grupo de estética (representações sociais: estética, diamante, paisagem; sentido de extraordinário); grupo de etnias (representações sociais: miscigenação e europeísmo). Nota-se que, entre as representações e sentidos que não participam desses seis grupos, as representações de ócio e comércio e o sentido de pluralidade, apenas este último reforça os critérios de tombamento. O sentido de pluralidade, vale lembrar, participava da listagem anterior, cujo escopo era formado pelas representações, pelos sentidos e pela referência que validavam os critérios da UNESCO.
Assim, concluí-se que seja pela primeira listagem, seja pela identificação de grupos, os critérios são validados por maioria - comprova-se: os grupos acima listados reúnem um expressivo número de representações, dentro da totalidade de 28 sites, autorizando, portanto, a considerar que, além de reforçar todos os critérios antes expostos, a maioria das representações contidas nesses grupos valida tais critérios. Ao validar a lista de critérios como um todo, os grupos assim formados concorrem para legitimar o tombamento mundial de cidades e sítios. Considera-se que esses grupos comprovam também que representações sociais revelam, com muita propriedade, os aspectos que ajudam a compreender os mecanismos de reconhecimento da coletividade no patrimônio. Contribuem, destarte, para realizar o que Henri-Pierre Jeudy expressa em La Machinerie Patrimoniale (2001): "É necessário, para que haja patrimônio reconhecível, gerenciável, que uma sociedade se assenhore dele como de um espelho dela mesma [...]" (JEUDY, 2001 p. 17, tradução nossa). ${ }^{2}$

\section{Considerações Finais}

Possibilitada pelo cumprimento de todos os procedimentos do método adotado, a constatação acima exposta finaliza a análise empírica. Atesta, portanto, a consecução do objetivo inicialmente colocado, inclusive externando as conclusões parciais possibilitadas pela detecção das representações sociais. Além disso, o trabalho permitiu provar a inexistência de um senso comum para a cidade brasileira patrimônio mundial e concluir que a diversidade cultural interna do país 
se reflete também na Web. Igualmente, possibilitou constatar a existência de grupos de representações e sentidos de mesma natureza, revelando suas origens como fenômenos. Ademais, propiciou a conclusão de que a maioria desses grupos valida a lista de critérios da UNESCO, contribuindo para legitimar o estatuto do tombamento mundial de cidades e sítios.

O percurso metodológico adotado igualmente permitiu confirmar que os sites têm nos aspectos multimídias e na interatividade os seus principais diferenciais como suportes narrativos de cidades, relativamente aos suportes que Ihes precederam no tempo (arquitetura como espaço construído, livros, revistas e jornais). As leituras de cidades em sites diferenciam-se das leituras dos suportes narrativos que os precederam, em especial, pelos seguintes aspectos implicados na leitura dos sites: a polifonia, dada à interatividade e à variedade discursiva; a permeabilidade e a capilaridade da Web, tornando a leitura um processo de errância por uma multiplicidade de camadas de informação e de canais.

Por fim, resta dizer que este trabalho permitiu constatar o quão apropriada é a teoria das representações sociais para o estudo de arquitetura, cidades e territorialidades em outros suportes narrativos. Endossando esta última consideração, ressalta-se que a teoria das representações sociais permite um mergulho aprofundado nos sentidos espaciais e urbanos.

\section{Referências bibliográficas}

BACHELARD, G. A poética do espaço. São Paulo: Martins Fontes, 1988

A água e os sonhos: ensaio sobre a imaginação da matéria. São Paulo: Martins Fontes, 1998.

A terra e os devaneios do repouso: ensaio sobre as imagens da intimidade. São Paulo: Martins Fontes, 1990

O ar e os sonhos: ensaio sobre a imaginação do movimento. São Paulo: Martins Fontes, 2001.

A psicanálise do fogo. São Paulo: Martins Fontes,

BANDEPE. Mapa interativo do Sítio Histórico de Olinda. Disponível em: <http://www.culturalbandepe.com. br/mapa/igrejasolinda.htm>. Acesso em: 7 jun. 2006.
BARTHES, R. A câmara clara: nota sobre a fotografia. Rio de Janeiro: Nova Fronteira, 1984.

BELLUZZO, A. M. O Brasil dos viajantes. São Paulo: Objetiva, 2000. v. 1

CHARANDEAU, P.; MAINGUENEAU, D. Dicionário de análise do discurso. 2. ed. São Paulo: Contexto, 2006.

DOLORES, M. Ouro de Minas. Viagem e Turismo, São Paulo, ano 12, n. 5, p. 90-91, maio 2006

ENCICLOPÉDIA Conhecer. São Paulo: Abril Cultural, 1972. p. $1138-1139$

HOUAISS, A. Dicionário eletrônico da língua portuguesa 1.0. Rio de Janeiro: Objetiva, 2001.

JEUDY, H-P. La machinerie patrimoniale. Paris: Sens \& Tonka, 2001.

JODELET, D. Representações sociais: um domínio em expansão. In: JODELET, D. (Org.). As representações sociais. Rio de Janeiro: EdUERJ, 2001. p. 17-44

LALANDE, A. Vocabulário técnico e crítico da Filosofia. São Paulo: Martins Fontes, 1999.

MANGUEL, A. Uma história da leitura. 2. ed. São Paulo: Companhia das Letras, 2001.

MOISÉS, M. Dicionário de termos literários. 11. ed. São Paulo: Cultrix, 2002

MOSCOVICI, S. Representações sociais: investigações em psicologia social. 2. ed. Petrópolis: Vozes, 2004

ROSSI, A. Arquitetura da cidade. São Paulo: Martins Fontes, 1998.

SÁ, C. P. A. A construção do objeto de pesquisa em representações sociais. Rio de Janeiro: EdUERJ, 1998.

UNESCO. Patrimônio mundial no Brasil. 3. ed. Brasília: UNESCO, 2004.

\section{Referências dos sites analisados}

A CIDADE de Brasília. Disponível em: <http://www.geo cities.com/TheTropics/3416/bsb port.htm>. Acesso em: 14 mar. 2008

ALBERGUE de Olinda. Olinda, 2008. Disponível em: <http://www.alberguedeolinda. com.br/apres.html> Acesso em: 8 fev. 2008

ALTIPLANO. Disponível em: <http://www.altiplano.com br/index.html>. Acesso em: 2 maio 2008.

BAHIA com.br. Salvador. Disponível em: <http://www. bahia.com.br/index.asp>. Acesso em: 4 mar. 2008.

BRASIL Viagem: destino Salvador. Rio de Janeiro: Urbi et Orbi, 2008. Disponível em: <http://www.brasilviagem.com/cidades/?CodCid=5>. Acesso em: 7 mar. 2008.

BRASIL Viagem: São Luís. Disponível em: <http://www. brasilviagem.com/cidades/? CodCid=27\&Lnk=1> Acesso em: 13 jun. 2008. 
BRASÍLIA Convention. Disponível em: <http://www.brasilianconvention.com.br /index.htm>. Acesso em: 20 mar. 2008.

BRASÍLIA patrimônio cultural da humanidade. Disponível em: <http://www.lavenere. com.br/patrimonio cultural/index3.htm>. Acesso em: 26 maio 2008.

BRAZIL on Board: Goiás Velho. Disponível em: <http:// www.brazilonboard.com/goias/23196.asp>. Acesso em: 17 jun. 2008.

CIDADE de Ouro Preto. Belo Horizonte: SN Designer, 2007. Disponível em: <http://www.cidadeouropreto. com.br/index.html>. Acesso em: 20 dez. 2007.

CIDADES históricas brasileiras: Diamantina. Disponível em: $<$ http://www.cidadeshistoricas. art.br/diamantina/> Acesso em: 23 abr. 2008.

CIDADES históricas brasileiras: Goias Velho. Disponível em: <http://www. cidadeshistoricas.art.br/goias/>. Acesso em: 6 maio 2008

CIDADES históricas brasileiras: Ouro Preto. Disponível em: $<$ http://www. cidadeshistoricas.art.br/ouropreto $>$. Acesso em: 6 jan. 2008.

CIDADES históricas brasileiras: São Luis. Disponível em: $<$ http://www.cidadeshistoricas. art.br/saoluis $>$. Acesso em: 5 abr. 2008.

DESCUBRA Minas: Diamantina. Belo Horizonte, 2008. Disponível em: <http://www. descubraminas. com.br/destinosturisticos/hpg_municipio.asp?id_ municipio=28>. Acesso em: 21 abr. 2008.

DIAMANTINA. Disponível em: <http://www.diamantina. com.br/>. Acesso em: 21 abr. 2008

EMTURSA. Salvador, 2008. Disponível em: <http:// www.emtursa.ba.gov.br/Template.asp?
IdEntidade $=1 \&$ Nive $=0001>$. Acesso em: $8 \mathrm{fev}$. 2008.

GOVERNO do Maranhão. Disponível em: <http://www. ma.gov.br/cidades/saoluis/ breve_historia/index. php>. Acesso em: 25 abr. 2007

GUIA de Brasília. Disponível em: <http://www.guiadebrasilia.com.br/indez.htm>. Acesso em: 20 mar. 2008.

IDAS Brasil: Diamantina. Disponível em: <http://www. idasbrasil.com.br/idasbrasil/ cidades/Diamantina/ port/apresent.asp/>. Acesso em: 26 abr. 2008.

OLINDA Online. Disponível em: <http://www.olinda.com br>. Acesso em: 22 jun. 2007

OLINDA Virtual. Disponível em: <http://www.olindavirtual. net>. Acesso em: 11 abr. 2007.

OURO Preto. Disponível em: <http://www.ouropreto.com. br>. Acesso em: 27 dez. 2007

PATRIMÔNIO da Humanidade. Disponível em: <http://www. patromonioslz.com.br>. Acesso em: 8 abr. 2008.

PREFEITURA Municipal de Olinda. Disponível em: <http:// www.olinda.pe.gov.br/portal/ guia locais pitorescos.php>. Acesso em: 24 jan. 2008.

SITE Oficial de Ouro Preto. Disponível em: <http://www. ouropreto.org.br>. Acesso em: 7 jan. 2008

VILA Boa de Goiás. Disponível em: <http://www.vilabo adegoias.com.br/cidade/cidade. htm>. Acesso em: 1 maio 2008.

VISITE a Bahia. Salvador, 2008. Disponível em: <http:// www.visiteabahia.com.br/ visite/salvador/index. php>. Acesso em: 25 fev. 2008. 


\title{
Seven cities: a study of social representations of brazilian cities world patrimony on the Web
}

Eliane Bevilacqua Lordello dos Santos Souza

\begin{abstract}
This article describes results and evolutions of the thesis of the same title, the object of which are the social representations in the Web of Brazilian cities, recorded as historical sites by UNESCO, to reveal them. Its main foundations are the cities narrative support, world patrimony, cultural diversity, and the theory of social representations. In the empirical study, such foundations are aligned with the methodology steps suggested by the theory of social representations, analytical-descriptive methods, and discourse analysis methods. The representations are revealed, evaluated as to the UNESCO recording criteria, and other investigations are suggested.
\end{abstract}

Keywords: social representations, world patrimony, websites.

\section{Siete ciudades: un estudio de las representaciones sociales de las ciudades brasileñas patrimonio mundial en la Web}

Eliane Bevilacqua Lordello dos Santos Souza

\section{Resumen}

Este artículo relata resultados y despliegues de la tesis del mismo nombre, que tiene por objetivo las representaciones sociales, en la Web, de las ciudades brasileñas preservadas por la UNESCO, proponiéndose a desvendar estas representaciones. Sus principales fundamentos son los soportes narrativos de ciudades; el patrimonio mundial; la diversidad cultural; la teoría de las representaciones sociales. Para el estudio empírico fueron aliados a tales fundamentos los pasos metodológicos sugeridos por la teoría de las representaciones sociales y los métodos analítico-descriptivos y de análisis del discurso. Las representaciones son desvendadas, son relativizadas en cuanto a los criterios de preservación de la UNESCO y otras investigaciones se sugieren.

Palabras clave: representaciones sociales, patrimonio mundial, websites. 